\title{
Are dislocated direct objects clause-external? Evidence from differential object marking
}

\author{
Giorgio Iemmolo
}

University of Zurich

\section{Introduction}

The aim of this paper is twofold. First, I examine the frequent cross-linguistic connection between Differential Object Marking (henceforth, DOM) and dislocated position, as well as the co-occurrence of DOM and Differential Object Indexation (henceforth, DOI) on the verb. Second, I discuss some severe problems these data pose for the fundamental assumption, shared by linguists of different theoretical persuasions, that i) verbal arguments can be expressed only once within the clause, and ii) that dislocated constituents have to be clause-external. In the remainder of this section I discuss the phenomena under analysis and the issues at stake. In section 1.1 I first examine the correlation between DOM and dislocation, and languages which show double marking of direct objects, i.e. both DOM and DOI. I then discuss the problems the examined data pose for the assumptions mentioned above in the treatment of argument structure. An alternative approach is proposed in section 3. Conclusions are drawn in section 4.

\subsection{DOM and DOI}

DOM is the phenomenon whereby some direct objects are overtly coded based on some semantic and pragmatic properties of their referents, such as animacy, definiteness, and topicality (Aissen 2003, Bossong 1985, Iemmolo 2011). This is illustrated by examples (1a) and (1b), which differ as to the morphological encoding 


\section{Giorgio Iemmolo}

of the direct object. In (1a), the direct object is followed by the postposition $r \hat{a}$, while in (1b) it is not. Tradiitonally, this difference is explained in terms of definiteness. Definite direct objects will be overtly coded, while indefinite ones will not:

a. Hasan ketab-râ did Hasan book-DOM see:3SG.PST

"Hasan saw the book

b. Hasan ketab did

Hasan book see:3SG.PST

"Hasan saw the book (Comrie 1989, 139)

In a substantial number of languages, DOM on the noun is complemented by DOI (often known as clitic doubling in Romance or Semitic languages) on the verb. For instance, in the Northeastern Neo-Aramaic dialect of Telkepe (Iraq) (Coghill 2010, to appear), DOM occurs solely in conjunction with DOI, while DOI can occur alone, as shown by examples (2a) and (2b):
a. kəm-šāqəl-lə
ta barāna

PST-take.3SG.M-OBJ.3SG.M DOM ram

"He took the ram

b. kəm-šāqəl-lə barāna

PST-take.3SG.M-OBJ.3SG.M ram

"He took the ram

Similar systems are rather widespread in the world's languages (Iemmolo 2011), and constitute a challenge for the assumption that an argument cannot be represented more than once within a clause.

\subsection{The clause-external status of dislocated constituents}

The term "dislocation" refers to a construction in which a constituent occurs at the left (i.e. left dislocation) or right (i.e. right-dislocation) edge of a sentence (Foley 2007, 443) and is (optionally, see below) resumed by a coreferential pronominal index within the clause, as in the English examples in (3) and (4):

(3) That book $_{[i]}$, I haven't read it ${ }_{[i]}$.

(4) I haven't read it $[i]$, that $\operatorname{book}_{[i]}$.

It is commonly assumed, both in functionally- and formally-oriented approaches, that dislocated constituents are outside clause boundaries, i.e. they represent a sort of adjunct to the clause and are not governed by the verb (Lambrecht 2001, Baker 1996, Foley 2007, 1065). Rather, it is the pronominal index that saturates the verb valency and thus constitutes the "real argument" of the verb. The full NPs are thus 


\section{Are dislocated direct objects clause-external? Evidence from differential object}

marking

"in apposition" to the clause and function as topical elements linked to the clause via an anaphoric relation expressed through the index on the verb.

This assumption follows directly from the principle, known under the label of "Functional Uniqueness condition" in Lexical-Functional Grammar (Bresnan 2001, 311) or "Theta-criterion" in different versions of generative grammar, that arguments cannot be mapped more than once within a predicate argument structure. A popular illustration of this principle comes from Chichêwa (Niger-Congo, Bantu). Chichêwa, as many other Bantu languages, displays DOI with topical objects (Bresnan and Mchombo 1987). According to Bresnan and Mchombo (1987)'s analysis, when present, DOI functions solely as an incorporated pronominal argument, and the NP coreferential with the indexation marker is a floating topic outside the clause. The contrast is exemplified by the following examples. In (5a), since there is DOI, the object must be generated in an adjoined-topic position and the actual argument is the pronominal index on the verb. In (5b), since there is no DOI, the DO is clause-internal and therefore does not trigger indexation.

a. Njûchi zi-ná-wá-lúm-a alenje bee.PL SUBJ.-PST-OBJ-bite-IND hunter.PL

"The bees bit them, the hunters"

b. Njûchi zi-ná-lúm-a alenje bee.PL SUBJ-PST-bite-IND hunter.PL

"The bees bit the hunters"

Similar analyses have been proposed for the so-called "pronominal argument languages" (Jelinek 1984, Baker 1996, 2003), like Mohawk (Iroquoian, Baker 1996) or a number of Australian languages (Jelinek 1984). Under this hypothesis, known as Pronominal Argument Hypothesis (PAH), independent NPs are "adjuncts" that occupy a position outside the clause boundaries (behaving thus like dislocated NPs). Again, the indexes are the true arguments of the verb, and sentences are complete without any overt NPs. I will not dwell on the specific problems raised by the PAH hypothesis directly (but see, e.g., Austin and Bresnan 1996, Evans 2002 for discussion and criticism). Here I will concentrate on the specific problem posed by the claims that i) dislocated NPs are universally clause-external, and ii) in presence of double marking, only one of the expressions is the argument of the verb. I will discuss this postulate with particular regard to the following parameters that have been proposed to define dislocated constituents, namely:

- presence of a resumptive pronominal index;

- special prosody (Lambrecht 2001);

- default case marking or no case marking (Baker 2003).

As we will see below, none of the parameters above is a necessary and sufficient condition for characterising a constituent as dislocated and thus extra-clausal. 


\section{Giorgio Iemmolo}

In fact, there are a number of languages where dislocated constituents are not resumed by any pronominal index, since not every language possesses them. Nor is special prosody, which usually amounts to an intonation break, necessarily present. Most important, as I will show in the next section with regard to DOM, the claim that dislocated NPs receive default case marking or no case marking at all (i.e. they are not subject to case checking, see Baker 2003, 125) does not hold true when empirical data are taken into account. If dislocated NPs are extra-clausal, how can we account for i) the presence of DOM with dislocated objects, and ii) the optionality of the pronominal element that occurs in some languages? These questions will be taken up in the next section.

\section{DOM, dislocation, and double marking}

The present study is based on a convenience sample of 133 languages showing DOM (Iemmolo 2011). As mentioned above, some languages also show indexation on the verb, thus giving rise to an (optional) double marking pattern. Each instance of DOM has been coded with respect to the main parameter(s) (i.ethe parameter that takes priority over the others) influencing the presence of overt coding of objects. The distribution of DOM relative to the main parameter is shown in Table (0.1):

\begin{tabular}{|l|r|r|}
\hline Parameter & No & \multicolumn{1}{l|}{$\%$} \\
\hline Animacy & 45 & 33,83 \\
\hline Topicality & 86 & 64,66 \\
\hline Dislocation & 60 & 45,11 \\
\hline Definiteness & 2 & 1,5 \\
\hline Total & 133 & 100 \\
\hline
\end{tabular}

Table 0.1: Distribution of DOM systems relative to the main parameter

As shown by Table (0.1), in 60 languages out of 133 (i.e. 45\%), the main parameter for DOM to appear is the dislocated position of the object (i.e. at the left or right edge of the sentence) A straightforward example comes from Purepecha, an isolate language spoken in Mexico, where there is obligatory DOM with human objects, as in (6a). With other kinds of objects, DOM is obligatory only if the object is dislocated, as shown by the opposition between (6b), with optional DOM when the object is in the normal final-sentence position, and (6c), where DOM cannot be omitted. It should be noted that dislocation in Purepecha does not involve any resumptive element.

a. ife- -ka-ni mananaka-*(ni) see-AOR-DECL.1/2SG-1SG a young_girl-DOM

"I saw a young woman" (Chamoreau 1999) 
Are dislocated direct objects clause-external? Evidence from differential object marking

b. Pedru míti-h-ti eski Juanu kaká-ka má

Pedro know-PFV-3SG.IND that Juan break-3SG-SUBJ one

tsúntsu-(ni)

pot-DOM

"Pedro knows that Juan broke a pot"

c. Má tsúntsu-*(ni) Pedru míti-h-ti eski Juanu

one pot-DOM Pedro know-PFV-3SG.IND that Juan

kaká-ka

break-3SG-SUBJ

"One pot, Pedro knows that Juan broke (it)" (Vázquez Rojas Maldonado 2010)

In Dullay (Afro-Asiatic. Cushitic), the situation is even more extreme, since only left-dislocated objects receive DOM obligatorily, while sentence-medial objects are only optionally marked: as illustrated by (7a) and (7b):

a. qawhó-n mi?é hí?í

man-DOM child see.PST.3SG

"The man, the child saw (him)"

b. mißé qawhó-n hî̉í

child man-DOM see.PST.3SG

"The child saw the man" (Tosco 1994, 238)

Similar systems are found in many unrelated language families, such as Altaic, Sino-Tibetan, Nilo-Saharan, Indo-European, Dravidian, etc. (see Iemmolo 2011 for discussion and examples). If we accept the idea that dislocated objects with DOM are clause-external constituents, then the next logical step would be to expect the object marker not to show up in those contexts, which should not be subject to verb government. An alternative analysis would be to consider the marker as a topic marker when it marks a dislocated object. This is not a viable solution, since it would lead to the conclusion that the same marker works as a topic marker with dislocated objects and as a case marker when the object is in situ. Moreover, the optional appearance of DOM with objects in their canonical position (usually next to the verb phrase) would make this analysis even more opportunistic. It can indeed be easily seen that in none of the examples I have just discussed can the objects be considered as clause-external based on the criteria listed in section 1.2.

Languages where DOM and DOI appear at the same time pose another serious challenge to the assumptions discussed above. I will discuss here the case of Romance languages, where the co-occurrence of DOM with clitic doubling has been extensively studied (see, e.g. Anagnostopoulou 2006, Leonetti 2008 and references therein). Spanish and Italian are a good case in point. DOM in Modern Peninsular Spanish is obligatory with definite human direct objects (Leonetti 2004, Tor- 


\section{Giorgio Iemmolo}

rego Salcedo 1999) ${ }^{1}$, while it is optional with indefinite specific and non-specific ones. The link within dislocation is still fairly strong, as shown by the fact that, with dislocated objects, DOM becomes obligatory even with objects for which DOM is optional when in post-verbal position. This is illustrated by the opposition between (8a) and (8b):

a. Ya conocía (a) muchos estudiantes

already know.IPFV.1SG DOM many students

"I already knew many students"

b. *(A) muchos estudiantes, ya los conocía

DOM many students already 3PL.OBJ know.IPFV.1SG

"Many students, I already knew (them)" (Leonetti 2004)

As expected, in the case of dislocation in (8b), there is a resumptive clitic element coreferential with the dislocated object. Under the assumption that the dislocated object is clause-external, the clitic would represent the argument of the verb. Still, this does not explain the obligatory presence of $a$ in (8b). The latter structure presents an obvious puzzle to theories that postulate the functional uniqueness principle. Even more puzzling are the examples where the object is in its canonical post verbal position, and yet the clitic is obligatory. This is found with pronominal objects, as exemplified by the ungrammaticality of (9a) as opposed to $9 b$ ):

$$
\begin{aligned}
& \text { a. *Vimos a él } \\
& \text { see.PST.1PL DOM him }
\end{aligned}
$$

"We saw him"

b. Lo vimos a él

3SG.M.OBJ see.PST.1PL DOM him

"We saw him" (Leonetti 2004)

In examples like (9b), one might legitimately wonder which constituent has argument status. One proposal, known in the generative literature as "Kayne's generalisation", tries to capture the close link between clitic doubling and DOM by stating that clitic doubling occurs only if the NP is preceded by the preposition $a$. Under this analysis, clitics "absorb" accusative case (representing thus the arguments) so that the full object NPs would appear caseless. However, this would violate the Case Filter. The insertion of the preposition then just functions as a case-saving device to avoid the lack of case on the object NP.

As has been pointed out by several scholars, this analysis is rather problematic, because it postulates that clitic doubling is dependent upon DOM. That this is not the case is demonstrated by the fact that clitic doubling can occur without DOM, as in (14a) and (14b).

${ }^{1}$ DOM with inanimate direct objects is not uncommon (Company Company 2002, García García 2007 among others) and suggests that DOM is extending downwards the animacy hierarchy. I will not go deeper into this issue here. 
Are dislocated direct objects clause-external? Evidence from differential object marking

a. Ya las lavé a todas already CLIT.3PL.F wash.1SG.PST DOM all.PL.F

"I already washed them all"

b. Ya las lavé todas

already CLIT.3PL.F wash.1SG.PST all.PL.F

"I already washed them all" (Mayer 2006)

Further, Kayne's generalisation remains fairly elusive on the key issue of this paper. If clitics absorb the argument position, but full NPs need to be case marked, it is unclear which constituent is to be considered the "argument". One analysis could be that, in presence of a case-marked noun, it is the noun that carries argument status, and its co-referential clitic is an indexation marker, as in (14a). In (14b), the lack of case marking on the object would lead to the conclusion that the object is an "adjunct" and the clitic an incorporated pronominal. However, in order to support this interpretation, we necessarily have to provide two different analyses for the very same element, i.e. the clitic. This constitutes one instance of what (Croft 2001) has called "methodological opportunism".

The Uniqueness Principle, as well as the extra-clausal nature of dislocated NPs, becomes even more difficult to support when empirical data from Italian are examined. Standard Italian, as well as Northern Italian varieties, are usually claimed to lack DOM and clitic doubling (Anagnostopoulou 2006 and references therein). However, as shown in Iemmolo 2010, Italian does show both constructions, albeit to a lesser degree than Spanish. Clitic doubling is obligatory with every dislocated object. DOM is restricted to first and second-person pronouns in dislocated position, where it is obligatory, as shown by examples (11a) and (11b). The omission of DOM renders the sentence ungrammatical, unless the object is a contrastive focus bearing prosodic stress:
a. *(A) me non (mi)
convince
questo

DOM me NEG CLIT.1SG convince.PRS.3SG this

"This does not convince me"

b. A me non convince questo

DOM me NEG convince.PRS.3SG this

“This does not convince me" (Iemmolo 2010, 249)

The evidence for the extra-clausal status of the pronominal object in (11a) is very controversial. First of all, no intonational break between the dislocated object and the rest of the sentence is present. Second, the clitic can be omitted, at least with some verbs classes ${ }^{2}$. If one assumes that the principles given above are correct, one

${ }^{2}$ Specifically, the omission of the clitic is possible when the governing predicate is either a psychological verb (as in the examples above), or a causative verb (fare/lasciare+infinitive). The exact details of such clitic omission have not been clearly understood yet, even though sociolinguistic factors seem to be at play (Iemmolo 2011). 


\section{Giorgio Iemmolo}

would have to analyse the object in (11a) as clause-external and the one in (11b) as clause-internal. It is by no means clear why this should be so. Indeed, this would lead to the conclusion that the preposition $a$ marks a core syntactic relation in one case and an adjunct in the other one. This is an unwarranted conclusion, and seems to be motivated only by purely theory-internal reasons.

Diachronic investigations also show that a close link between DOM and DOI does exist. As shown by Melis (1995), Pensado (1995), Laca (2006), DOM in Old Spanish was primarily governed by the topicality of the object. In particular, according to (Pensado 1995), DOM in Spanish indeed arose in left dislocations of personal pronouns to encode the object as a topic. The examples in (9b) from the Cantar de mio Cid nicely illustrate the connection with dislocation. When the object is post-verbal, there is no DOM, as in (12a). By contrast, when the object is pre-verbal, as in (12b), DOM shows up as expected:
a. Ca yo
case
sus fijas
con yfantes de

that 1SG.SUB marry.PST.1SG POSS.3PL daughters with princes of

\section{Carrion}

\section{Carrion}

"That I married off his daughters to the Princes of Carrion" (Cantar de mio Cid, 2956; 13th century)

b. Que a mis fijas bien las casare

that DOM POSS.1PL daughters good 3PL.F.OBJ marry.FUT.1SG yo

\section{SG.SUBJ}

"That my daughters, I will marry them well" (2834; examples from Melis 1995)

Likewise, in Old Sicilian (Iemmolo 2010), and in Persian (Windfuhr 1979, Windfuhr and Perry 2009), DOM first emerged in left dislocation and was later extended to objects in the canonical sentence position.

Even more severe problems are posed by the so-called "double-marking languages" (Nichols 1986, Bickel and Nichols 2007), where the simultaneous presence of object indexation and case marking on the NP is obligatory. An example of such a language is Belhare, a Tibeto-Burman language spoken in Nepal, where overt argument NPs (i.e. both agents and objects) are obligatorily case-marked and indexed on the verb, as shown by example (13):

$$
\begin{aligned}
& \text { kubay-chi-na pitcha-chi } \quad n \text {-ten-he-chi } \\
& \text { monkey-NSG-ERG child-NSG-ABS 3NSG.A-hit-PST-3NS.P }
\end{aligned}
$$

"The monkeys hit the children" (Nichols and Bickel 2011)

Grammatically, Belhare is a pro-drop language: overt argument NPs are never obligatory syntactically and a sentence is complete without any overt NPs, which 


\section{Are dislocated direct objects clause-external? Evidence from differential object}

marking

should then be analysed as "adjuncts". However, the fact that, when they are overtly expressed, they must receive overt case, casts doubts upon the universal validity of the Uniqueness principle.

If this analysis is extended to every pro-drop language, the logical conclusion would be that, in the absence of an overt NP, the index on the verb saturates the valency and thus functions as an incorporated pronominal argument, while it is a mere indexation marker when an overt NP is present. This is indeed what Jelinek (1984, 48-49) claims about Spanish subject indexation. As is well known, in Spanish (as well as in many other Romance languages) subject NPs are normally dropped, as can be seen in examples (8a, 8b, 9a, 9b). When overtly expressed, they have an "emphatic, contrastive" value or serve to shift the topic or introduce a new one into the discourse, as shown by the opposition between (14a) and (14b):

a. Está en la calle

be.PRS.3SG in the street

"S/he is in the street"

b. Ella está en la calle

she be.PRS.3SG in the street

"She is in the street" (personal knowledge)

This interpretation is highly debatable, as there are no grounds for assuming that overt pronominal subjects are in apposition to the sentence, apart from the theoretical postulate that arguments cannot be expressed more than once. Rather, as I will suggest in the next section, the issue of the double representation of arguments within a clause is better explained by appealing to functional considerations on the one hand and diachronic scenarios on the other one.

\section{A unified approach}

We have seen in the previous sections that crosslinguistic data show that DOM systems tend to be associated with dislocation. This fact goes against the widespread assumption that dislocated constituents are extraclausal and thus with no government relationship to the predicate. Furthermore, DOM often co-occurs with DOI, a fact that represents a puzzle for another related assumption in linguistic theory, namely that arguments cannot be expressed more than once within a clause.

I believe that these two assumptions should be abandoned as theoretical principles and a language-specific approach adopted. In order to account for the crosslinguistic variation found in this domain, one should ideally rely on formal and functional criteria to decide whether a NP is governed or not by the predicate. Similarly, the Uniqueness principle can be simply restated as a gradient phenomenon which depends upon language-specific criteria. This approach allows us to account for the large range of variation found among the world's languages as to the possible co-occurrence of an overt NP with indexation on the verb, without making any a priori assumptions which are not borne out by the data. 


\section{Giorgio Iemmolo}

Let us review the arguments in support of this hypothesis. First, as we have seen in the preceding sections, the presence of case marking is a decisive criterion: if a constituent receives the same case marking it would receive if it were in "normal" position, then it is by no means clear why one should assume that it is extraclausal, especially when also other criteria, such as the presence of an intonation break, do not give any additional supporting evidence. Thus, one can have languages like colloquial English or French, where dislocated constituents are truly clauseexternal, separated by a break from the clause, and a "default" case form is used regardless of the role of the coreferential NP within the clause, as exemplified by (15):

$$
\begin{aligned}
& \text { Moi, je ne le sais pas } \\
& \text { Me, I NEG CLIT.3SG.M know.PRS.1SG NEG } \\
& \text { "ME, I don't know" (personal knowledge) }
\end{aligned}
$$

Nonetheless, I hope to have shown that this pattern cannot be taken as universal, given the large number of languages where dislocated objects receive the expected case marking and do not show any other feature typical of dislocated constituents. This fact brings into question the recurrent co-occurrence of DOM and DOI and the issue of functional uniqueness. We have seen that, in order to preserve this theoretical postulate, one would be forced to analyse the indexation markers on the verb in a different way (either as an incorporated pronominal or as indexation) based on the presence vs. absence of an overt (case-marked) NP. The empirical evidence for such an analysis is fairly thin and inconclusive. First, as many linguists have observed, there are no clear criteria for distinguishing between "true" indexation and pronominal "anaphoric" indexation either on synchronic or diachronic grounds (Barlow 1992, Corbett 2003, Givón 1976, Lehmann 1988). Moreover, the existence of double marking, either optional, as in the case of DOM and DOI, or obligatory, as in Belhare, seriously undermines the cogency of this distinction.

This problem can be easily solved, in my opinion, by simply taking into consideration the fact that case marking and indexation are two distinct constructions, from a structural, functional and historical point of view (Croft 2001, Givón 1976, Siewierska 1999). As discussed in Iemmolo (2011), DOM and DOI systems are governed by the very same parameters and both tend to appear with topical objects. The role of topicality, however, is different in the two constructions. DOM is primarily a means of indicating topic discontinuities, such as topic shifts or topic reintroductions, while DOI is a means of maintaining topic continuity throughout the discourse. This functional difference explains the frequent association of DOM with dislocations and topicalisations, since these structures are means of putting a constituent in topical position. DOI is instead a device for encoding highly accessible referents, thus constituting a reference-tracking strategy (Barlow 1992, Givón 1983; Siewierska 2004, ch. 5). For this reason, DOI often occurs without a coreferential overt NP. If we take indexation as a discourse relation between a syn- 


\section{Are dislocated direct objects clause-external? Evidence from differential object marking}

tactic element (be it an NP, a pronoun, etc.) and a discourse referent (as proposed, e.g. by Croft 2001, 226, following a previous proposal by Barlow 1992), then it is perfectly plausible to have more than one realisation of a discourse referent within a clause. Similarly to what we have seen regarding dislocated NPs, we find a lot of variation in the world's languages as to the co-occurrence with an overt NP. There are languages where this co-occurrence is possible (like in many languages with both DOM and DOI), obligatory (as in double-marking language like Belhare). In languages where the co-occurrence is possible but not obligatory, the double representation of the argument may signal a difference in information structure, as in the Spanish or Italian cases discussed above. Over time, due to grammaticalisation (specifically to generalisation), the link with information structure might be weakened and the construction with the overt expression of both arguments might be reanalysed as pragmatically neutral. This process seems to be taking place in (Standard) Spanish, where, as we have seen above, DOI is already obligatory with case-marked pronominal objects. In other languages, we can have the exact reverse process whereby double representation is prohibited and thus no co-occurrence is possible. Such a system is exemplified by Noon, a Niger-Congo language spoken in Senegal, where only pronominal animate objects are indexed on the verb, while inanimate pronominal objects and full lexical NPs are expressed by independent forms and cannot be indexed on the verb (Soukka 2000):

a. Mi hay-yaa ki-wo'

1SG AUX.FUT-2SG.OBJ INF-tell

"I will tell you"

b. Mi hay-yaa ki-wo' beti-caa

1SG AUX.FUT INF-tell women-DEF

"I will tell the women" (Soukka 2000, 195)

In this case, the most plausible diachronic scenario appears to be one involving a process of restriction. Since, as we have discussed above, indexation is mainly used to refer to highly accessible referents (which, not incidentally, tend to be animate and definite), then it comes as no surprise that in some languages bound markers are grammaticalised as markers of topic continuity, thus maintaining the link with information structure.

What remains to be explained now is why DOM and DOI often co-occur. Such a co-occurrence is often regarded as a "redundancy" in the in the descriptive grammars of some languages. I believe that the functional differentiation outlined above between DOM and DOI is very helpful in explaining this co-occurrence. The different functions covered by the two construction, namely the indication of topic discontinuity vs. topic continuity, obey Lambrecht $(1994,184)$ 's "Principle of the Separation of reference and role" (PSRR). According to this principle, speakers tend to avoid structures in which a referent is introduced and commented upon at the same time. In these cases, speakers often resort to dislocation constructions, 


\section{Giorgio Iemmolo}

which allow the establishment of the lexical NP as a topic, which is later on referred to via an indexation marker. Hence, after being lexically referred to, a referent can be encoded as the normal "unmarked" topic expression, i.e. as a pronoun. The differences between DOM and DOI, as well as their co-occurrence, therefore comply with the requirement of the PSRR, in that DOM serves to introduce the topic which will be later encoded as a normal topic expression through DOI.

Since case and indexation are two distinct constructions, the question of which one is the "real" argument of the verb is no longer relevant. Rather, it is more reasonable to assume that they occupy two different argument slots and are governed by different rules (Croft 2001, 229, 272 ff., Schultze-Bernd 2011). Of course, the exact details of the co-occurrence of case or overt NPs and indexation in individual languages will be regulated by language-specific constraints. The evidence adduced thus far then calls for a revision of the Uniqueness Principle. In the discourse-based approach like the one adopted in this paper, the Uniqueness Principle would be recast in semantic/pragmatic terms. Basically, it serves to rule out the possibility for the same argument to be represented by two (or more) expressions that do not have the same referent. That is, both expressions must refer to the same referent (see Barlow 1992, Croft 2001), thus excluding sentences like (17), in which the two expressions refer to different discourse referents, namely a first person participant (me) and a second person one ( $t i)$.

$$
\begin{aligned}
& \text { *A me } e_{[i]} \text { non } t i_{[i]} \quad \text { convince questo } \\
& \text { DOM me NEG CLIT.2SG convince.PRS.3SG this }
\end{aligned}
$$

"This does not convince me"

\section{Conclusion}

DOM and DOI systems provide a profound challenge to some general assumptions widely accepted in different theoretical frameworks, in that they raise significant questions for i) the idea that arguments must be expressed only once in a clause and ii) the clause-external status of dislocated constituents. This paper has presented an alternative approach to the analysis of dislocated constituents and the issue of double representation of arguments, in which the universality of these postulates is rejected based on the examination of a range of cross-linguistic data. First, I have argued that the frequent diachronic and synchronic connection of DOM with dislocation makes it difficult to maintain the assumption that dislocated NPs are invariably extraclausal. Second, I have shown that double representation of an argument, by means of a case-marked lexical NP and indexation, can be easily explained by taking into account the fundamental discourse-functional difference between these two constructions. With particular regard to indexation, I have argued that the co-occurrence of an overt NP is the result of two different grammaticalisation processes, namely extension (which allows the co-occurrence) and restriction (which bans it). It is hoped that the account presented here is a first step towards 
Are dislocated direct objects clause-external? Evidence from differential object marking

the solution to the important descriptive and theoretical problems raised by the data presented in this paper.

\section{References}

Aissen, Judith, 2003. Differential object marking: iconicity vs. economy. Natural Language and Linguistic Theory 21:435-448.

Anagnostopoulou, Elena, 2006. Clitic Doubling. In Everaert Martin and Henk van Riemsdijk, eds., The Blackwell companion to syntax, volume 1, 519-581. Oxford: Blackwell.

Austin, Peter and Bresnan, Joan, 1996. Non-Configurationality in Australian Aboriginal Languages. Natural Language and Linguistic Theory 14(2):pp. 215268.

Baker, Mark, 1996. The polysynthesis parameter. Oxford Studies in Comparative Syntax, New York: Oxford University Press.

Baker, Mark, 2003. Agreement, dislocation, and partial configurationality. In Heidi Harley Carnie, Andrew and Mary Ann Willie, eds., Formal approaches to function in grammar. In honor of Eloise Jelinek, 107-132. AmsterdamPhiladelphia: John Benjamins.

Barlow, Michael, 1992. A situated theory of agreement. New York: Garland.

Bickel, Balthsar and Nichols, Johanna, 2007. Inflectional morphology. In Timothy Shopen, ed., Language Typology and Syntactic description, volume 2, 169-240. Cambridge: Cambridge University Press.

Bossong, Georg, 1985. Differentielle objektmarkierung in den Neuiranischen Sprachen. Tübingen: Narr.

Bresnan, Joan, 2001. Lexical-Functional Syntax. Oxford: Blackwell.

Bresnan, Joan and Mchombo, Sam A., 1987. Topic, pronoun, and agreement in Chichewa. Language 63(4):741-782.

Chamoreau, Claudine, 1999. Le marquage différentiel de l'objet en purépecha. La Linguistique 35(2):99-114.

Coghill, Eleanor, 2010. Ditransitive constructions in the Neo-Aramaic dialect of Telkepe. In Martin Haspelmath Malchukov, Andrej and Bernard Comrie, eds., Studies in ditransitive constructions: a comparative handbook, 221-242. Berlin-New York: Mouton de Gruyter.

Coghill, Eleanor, to appear. Differential object marking in Neo-Aramaic. Linguistics Special issue on Differential object marking: theoretical and empirical issues, Iemmolo Giorgio and Gerson Klumpp (eds.).

Company Company, Concepción, 2002. Grammaticalization and category weakness. In Ilse Wischer and Gabriele Diewald, eds., New reflections on grammaticalization, 201-215. Amsterdam-Philadelphia: John Benjamins.

Comrie, Bernard, 1989. Language typology and linguistic universals. Syntax and morphology. Oxford: Blackwell. 
Giorgio Iemmolo

Corbett, Greville, 2003. Agreement. Cambridge: Cambridge University Press.

Croft, William, 2001. Radical Construction Grammar. Oxford: Oxford University Press.

Evans, Nicholas, 2002. The true status of grammatical object affixes: evidence from Bininj Gunwok. In Nicholas Evans and Hans-Jürgen Sasse, eds., Problems of polysynthesis, 15-50. Berlin: Akademie Verlag.

Foley, William, 2007. Typology of Information Packaging in the Clause. In Timothy Shopen, ed., Language Typology and Syntactic description, volume 3, 362-446. Cambridge: Cambridge University Press.

García García, Marco, 2007. Differential object marking with inanimate objects. In Manuel Leonetti and Georg Kaiser, eds., Proceedings of the workshop "Definiteness, specificity and animacy in Ibero-Romance languages”, 63?84. Konstanz: Fachbereich Sprachwissenschaft, Universität Konstanz.

Givón, Talmy, 1976. Topic, pronoun and grammatical agreement. In Charles Li, ed., Subject and topic, 149-188. London-New York: Academic Press.

Givón, Talmy, 1983. Topic continuity in discourse: an introduction. In Talmy Givón, ed., Topic continuity in discourse. A quantitative cross-language study, 1-43. Amsterdam-Philadelphia: John Benjamins.

Iemmolo, Giorgio, 2010. Topicality and differential object marking: evidence from Romance and beyond. Studies in Language 34(2):239-272.

Iemmolo, Giorgio, 2011. Towards a typological study of differential object marking and differential object indexation. Ph.D. thesis, University of Pavia.

Jelinek, Eloise, 1984. Empty categories, case, and configurationality. Natural Language and Linguistic Theory 2(1):39-76.

Laca, Brenda, 2006. El objeto directo. La marcación preposicional. In Concepción Company-Company, ed., Sintaxis histórica del español. Primera parte: La frase verbal, Lengua y Estudios Literarios, volume 1, 423-475. Mexico: Fondo de cultura económica y Universidad Nacional Autónoma de México.

Lambrecht, Knud, 1994. Information structure and sentence form: topic, focus, and the mental representation of discourse referents. Cambridge: Cambridge University Press.

Lambrecht, Knud, 2001. Dislocation. In Martin Haspelmath, Ekkehard König, Wulf Oesterreicher, and Wolfgang Raible, eds., Language universals and language typology: an international handbook, 1050-1078. Berlin-New York: Mouton de Gruyter.

Lehmann, Christian, 1988. On the function of agreement. In Michael Barlow and Charles Ferguson, eds., Agreement in Natural Language, 55-67. Stanford: CSLI Publications.

Leonetti, Manuel, 2004. Specificity and differential object marking in Spanish. Catalan Journal of Linguistics 3(1):75-114.

Leonetti, Manuel, 2008. Specificity in clitic doubling and in differential object marking. Probus 20(1):35-69.

Mayer, Elisabeth, 2006. Optional Direct Object Clitic Doubling in Limeño Span- 
Are dislocated direct objects clause-external? Evidence from differential object marking

ish. In Miriam Butt and Tracy Holloway King, eds., Proceedings of LFG06. Stanford: CSLI Publications.

Melis, Chantal, 1995. El objeto directo personal en El Cantar de Mio Cid. Estudio sintàctico-pragmàtico. In Carmen Pensado, ed., El complemento directo preposicional, 133-163. Madrid: Visor Libros.

Nichols, Johanna, 1986. Head-Marking and Dependent-Marking Grammar. Language 66:56-119.

Nichols, Johanna and Bickel, Balthasar, 2011. Locus of Marking in the Clause. In Matthew S. Dryer and Martin Haspelmath, eds., The World Atlas of Language Structures Online. Munich: Max Planck Digital Library. URL http: //wals.info/chapter/23.

Pensado, Carmen, 1995. La creación del objeto directo preposicional y la flexión de los pronombres personales en las lenguas románicas. In Carmen Pensado, ed., El complemento directo preposicional, 179-233. Madrid: Visor Libros.

Schultze-Bernd, Eva, 2011. Looking for the governor, or the problem of argument status in double-marking languages. A Conctruction Grammar perspective. In Presentation given at the workshop "the conference "Explorations in Syntactic Government and Subcategorisation". Cambridge, UK, September 1, 2011.

Siewierska, Anna, 1999. From anaphoric pronoun to grammatical agreement marker: why objects don't make it. Folia Linguistica 33(1-2):225-251.

Siewierska, Anna, 2004. Person. Cambridge: Cambridge University Press.

Soukka, Maria, 2000. A Descriptive Grammar of Noon, Lincom Studies in African Linguistics, volume 40. Munich: Lincom Europa.

Torrego Salcedo, Ester, 1999. El complemento directo preposicional. In Ignacio Bosque and Violeta De Monte, eds., Gramàtica descriptiva de la Lengua Española, volume 2, 1779-1805. Madrid: Espasa.

Tosco, Mauro, 1994. On case marking in the Ethiopian language area (with special reference to subject marking in East Cushitic). In Vermondo Brugnatelli, ed., Sem Cam Iafet. Atti della 7 a Giornata di Studi Camito-Semitici e Indeuropei, 225-244. Milano: Centro Studi Camito-Semitici.

Vázquez Rojas Maldonado, Violeta, 2010. Case marking and semantic incorporation in Tarascan. Ms. New York University.

Windfuhr, Gernot, 1979. Persian grammar: history and state of its study. Trends in Linguistics. State-of-the-Art Reports, Mouton de Gruyter.

Windfuhr, Gernot and Perry, John R., 2009. Persian and Tajik. In Gernot Windfuhr, ed., The Iranian languages, 416-544. London: Routledge.

Giorgio Iemmolo

Seminar für Allgemeine Sprachwissenschaft

University of Zurich

Plattenstrasse 54. CH-8032 Zurich, Switzerland.

giorgio.iemmolo@uzh.ch 